\title{
Modifying the brain activation of poor readers during sentence comprehension with extended remedial instruction: A longitudinal study of neuroplasticity
}

\author{
Ann Meyler ${ }^{\mathrm{a}}$, Timothy A. Keller ${ }^{\mathrm{a}}$, Vladimir L. Cherkassky ${ }^{\mathrm{a}}$, John D.E. Gabrieli ${ }^{\mathrm{b}}$, Marcel Adam Just ${ }^{\mathrm{a}, *}$ \\ a Center for Cognitive Brain Imaging, Department of Psychology, Carnegie Mellon University, United States \\ b Department of Brain and Cognitive Sciences, Massachusetts Institute of Technology, United States
}

\section{A R T I C L E I N F O}

\section{Article history:}

Received 31 May 2007

Received in revised form 18 January 2008

Accepted 10 March 2008

Available online 25 March 2008

\section{Keywords:}

Dyslexia

Phonology

Reading ability

Neuroimaging

Treatment

\begin{abstract}
A B S T R A C
This study used fMRI to longitudinally assess the impact of intensive remedial instruction on cortical activation among 5th grade poor readers during a sentence comprehension task. The children were tested at three time points: prior to remediation, after $100 \mathrm{~h}$ of intensive instruction, and 1 year after the instruction had ended. Changes in brain activation were also measured among 5th grade good readers at the same time points for comparison. The central finding was that prior to instruction, the poor readers had significantly less activation than good readers bilaterally in the parietal cortex. Immediately after instruction, poor readers made substantial gains in reading ability, and demonstrated significantly increased activation in the left angular gyrus and the left superior parietal lobule. Activation in these regions continued to increase among poor readers 1 year post-remediation, resulting in a normalization of the activation. These results are interpreted as reflecting changes in the processes involved in word-level and sentencelevel assembly. Areas of overactivation were also found among poor readers in the medial frontal cortex, possibly indicating a more effortful and attentionally guided reading strategy.
\end{abstract}

(c) 2008 Elsevier Ltd. All rights reserved.

\section{Introduction}

Reading is among the most important of academic skills, affecting almost every aspect of a student's learning. Despite its centrality as the bootstrap to other learning, reading remains a problematic skill for many children, which if left unremediated, continues to hinder academic progress (Shaywitz, 2003). In modern literate society, the academic, social, emotional, and economic consequences of reading problems can be profound and far-reaching. Therefore, it is critical to understanding the nature of reading problems, and how to remediate them in a timely and effective manner. In recent years functional neuroimaging research has contributed to this objective, advancing our knowledge of the brain mechanisms underlying poor reading, and shedding light on the cognitive changes associated with remedial intervention.

The central goal of our study was to examine how reading remediation affects brain activation among poor readers when they are reading sentences for comprehension, a question that has not yet been explored. This issue is important because reading for meaning is ultimately the purpose of learning to read. A secondary goal in

\footnotetext{
* Corresponding author at: Carnegie Mellon University, Center for Cognitive Brain Imaging, Department of Psychology, Baker Hall, Pittsburgh, PA 15213, United States. Tel.: +1 412268 2791; fax: +1 4122682804 .

E-mail address: just@cmu.edu (M.A. Just).
}

this study was to examine the long-term effects of reading remediation on the brain. Specifically, the study evaluated the extent to which any neural change observed immediately following remedial treatment was maintained 1-year post-treatment. This longitudinal approach allowed us to determine whether alterations in brain function are transient, or whether they reflect more permanent consequences of intervention.

The large majority of neuroimaging studies investigating the neurobiological correlates of poor reading have concentrated on lower-level reading tasks involving letters and words. One of the most consistent results in these studies is a finding of reduced or absent activation among poor readers in the left parietotemporal and/or occipito-temporal cortices (e.g. Aylward et al., 2003; Brunswick, McCroy, Price, Frith, \& Frith, 1999; Corina et al., 2001; Eden et al., 2004; Georgiewa et al., 1999; Hoeft et al., 2006, 2007; Paulesu et al., 1996; Rumsey et al., 1992, 1997; Shaywitz et al., 1998, 2002, 2003, 2004; Simos, Breier, Fletcher, Bergman, \& Papanicolaou, 2000; Simos et al., 2002; Temple et al., 2003). While only a few studies have examined cortical function among poor readers in higher-level reading tasks, evidence is beginning to emerge indicating that underactivation in the parietotemporal and occipito-temporal regions may likewise characterize poor readers when they are reading sentences for comprehension (e.g. Kronbichler et al., 2006; Meyler et al., 2007; Seki et al., 2001). Together, the findings from word-level and sentence-level studies support the view that underfunctioning of these regions represents 
a neural signature of poor reading ability (e.g. Shaywitz \& Shaywitz, 2005).

The normal development of reading skills occurs across an extended period of time during childhood, and the role that different cortical areas play may differ over the course of reading acquisition. The left parieto-temporal region (including the posterior aspects of the superior and middle temporal gyri, the supramarginal gyrus and the angular gyrus), is thought to play a key role in phonological decoding (mapping print to sound) at the level of words. It has also been suggested that this region may function as a sound-based medium for storing and integrating phonological, semantic and syntactic information in verbal working memory at the level of sentence processing (Keller, Carpenter, \& Just, 2001). After sound-based word recognition skills become more automatic and fluent, the occipito-temporal cortex becomes increasingly involved in reading, and direct visual access to the mental lexicon eventually becomes the predominant reading strategy (Pugh, Mencl, Jenner, et al., 2000; Shaywitz et al., 2002). Thus, the parieto-temporal region is held to serve a more critical function in the earlier stages of reading acquisition.

A weakness in phonological processing is the hallmark readingrelated deficit for the large majority of struggling readers. This seems to be the case independently of factors such as general intelligence and socioeconomic disadvantage (Samuelsson \& Lundberg, 2003; Stanovich \& Siegal, 1994) although these variables can influence the expression of phonological ability (Noble, Wolmetz, Ochs, Farah, \& McCandliss, 2006; Samuelsson et al., 2006). Deficits in phonological processing are manifested as difficulty in analyzing and manipulating the constituent sounds in words, leading to difficulty in the acquisition of grapheme-phoneme knowledge, and subsequently, to poor word-decoding ability (Shaywitz, 2003; Wagner \& Torgesen, 1987). Behavioral research has shown that most poor readers benefit from a similar approach to instruction, namely, one in which explicit training of phonological skills is a central component (Blachman et al., 2004; Vellutino, Fletcher, Snowling, \& Scanlon, 2004).

Recent neuroimaging studies carried out at the word level have provided some insight into how phonologically based reading instruction influences cortical functioning among struggling readers. A consistent result emerging from these studies is that remedial treatment increases not only reading ability in impaired readers (measured behaviorally), but also the activation in the left parieto-temporal cortex, as measured by functional neuroimaging techniques (Aylward et al., 2003; Eden et al., 2004; Shaywitz et al., 2004; Simos et al., 2002; Temple et al., 2003). Thus, this formerly underactivating region becomes more active following effective instruction, essentially resulting in a normalization of function.

To date, it is not yet known how reading remediation influences cortical activation in higher-level tasks such as reading text. The present study addressed this question by examining brain activation among school-aged poor readers while they performed a sentence comprehension task at three time points: before remediation, immediately after remediation, and 1 year post-instruction. For comparison, good readers of the same age and from the same schools were also tested at the same time points.

\section{Methods}

\subsection{Participants}

The sample included good and poor readers in the 5 th grade from public schools surrounding Pittsburgh in Allegheny County, Pennsylvania. The poor readers were a subset of participants in the Power4Kids Reading Initiative: a randomized trial, field study of remedial instruction for children with a wide range of reading difficulties. (For a full description see Torgesen et al., 2006.) Criteria for inclusion in the project were a score at or below the 30th percentile on the combination of the Sight Word Efficiency (SWE) and phonological decoding subtests of the Test of Word Reading
Efficiency (TOWRE; Torgesen, Wagner, \& Rashotte, 1999), and a score at or above the 5th percentile on the Peabody Picture Vocabulary Test (PPVT; Dunn \& Dunn, 1997). Good readers (designated as average to above average by their teachers) were recruited for the fMRI study from the same schools. Twenty-three poor readers and 12 good readers were eligible at both pre-intervention and post-intervention phases. At the time of the 1 -year follow-up, 10 good readers and 18 poor readers remained in the sample. ${ }^{1}$ The participants were all right-handed, native English speakers, with normal vision and hearing. Children were excluded from the study if they had brain injury, sensory disorders, psychiatric disorders, attention deficit disorder, were on medication, had any metal in their bodies, or were claustrophobic. All included children exhibited head motion below $3 \mathrm{~mm}$ and achieved an accuracy rate of at least $75 \%$ on the experimental task.

Parents received explanatory materials about the reading project in the mail, including the Power4Kids voluntary fMRI study, and those expressing interest in the fMRI study were recruited. The children gave verbal informed consent in the presence of a parent or guardian, who gave signed informed consent. The children were paid for their participation. A parent questionnaire was used to verify that all participants met inclusion criteria. All protocols were approved by the University of Pittsburgh and Carnegie Mellon University Institutional Review Boards.

\subsection{Remedial instruction}

The Power4Kids project used four reading programs: Corrective Reading, Wilson Reading, Spell Read Phonological Auditory Training (PAT), and Failure Free Reading, each of which has been shown to be highly effective in teaching struggling readers (Torgesen et al., 2006). The original design of the large-scale Power4Kids project was intended to compare the efficacy of these four programs, including a comparison between those programs that focused on word-level instruction with those that included both word-level instruction and additional instruction on comprehension. However, as described in Appendix A, the differences among the programs had little differential impact on the behavioral (because of the small effect sizes) or on the brain activity findings (because of the small sample sizes), and the data from the four instruction groups are combined for all analyses presented here.

\subsection{Behavioral measures}

To assess the behavioral effects of reading remediation, out-of-magnet performance among good and poor readers was assessed on the basis of gradestandardized TOWRE scores (consisting of Sight Word Efficiency and Phonological Decoding Efficiency (PDE) subtests) at each stage of the study. An additional measure of calculation ability from the Woodcock-Johnson III Tests of Achievement (WJ-III; Woodcock, McGrew, \& Mather, 2001) was also collected. These data were obtained for both groups of readers in the pre-intervention and 1-year follow-up phases, and an additional assessment of only poor readers was conducted at the immediate post-intervention phase.

\subsection{Experimental paradigm}

At each stage of the study, participants performed an identical sentence comprehension task. In this task, the children decided whether a sentence they read made sense or not, as shown in Fig. 1. This task was designed to be well within the reading ability of the poorest readers on the basis of a pilot study, to minimize performance-related confounds by assuring high accuracy rates. A Sensibility (Nonsense vs. Sensible) $\times$ Syntactic Complexity (Active vs. Passive) blocked design was used. The data acquisition was split into consecutive runs to reduce the length of time children had to remain still while they concentrated on the task. Each run consisted of four stimulus blocks, one of each type. Five fixation blocks of $15 \mathrm{~s}$ each were interleaved with the four stimulus blocks to provide a control baseline comparison. The fixation consisted of a plus sign (+) centered on the screen. The probe, "Makes Sense?" appeared at the beginning of each block. The probe was presented for $1.6 \mathrm{~s}$ followed by a 400 -ms blank screen. Each block contained five stimulus sentences, one of which was a randomly placed sense-judgment distracter (i.e., for the Sensible blocks one of the five sentences was a non-sensible sentence, and for the Nonsense blocks, one of the five sentences was a sensible sentence). Each sentence trial was $10 \mathrm{~s}$ in length: the sentence itself was presented in the middle of the screen for $9.5 \mathrm{~s}$, followed by a $500-\mathrm{ms}$ blank screen. An asterisk appeared at $8 \mathrm{~s}$ into the trial below the sentence to cue the participant if they had not yet responded. Participants used a right-hand button-press to indicate "sensible", and a left-hand press for "not sensible." The words, "No" and "Yes" appeared at the bottom left and right corners

1 Third grade children were also assessed at the same time points. Although the observed effects in the third graders were similar to those in the fifth graders, the data were noisier, resulting in lower levels of statistical reliability and some differences in the precise localization of effects at different ages. For this reason, only data for the older age group are presented here. A full report of pre-treatment differences in activation between good and poor readers in the third grade can be found in Meyler et al. (2007). 


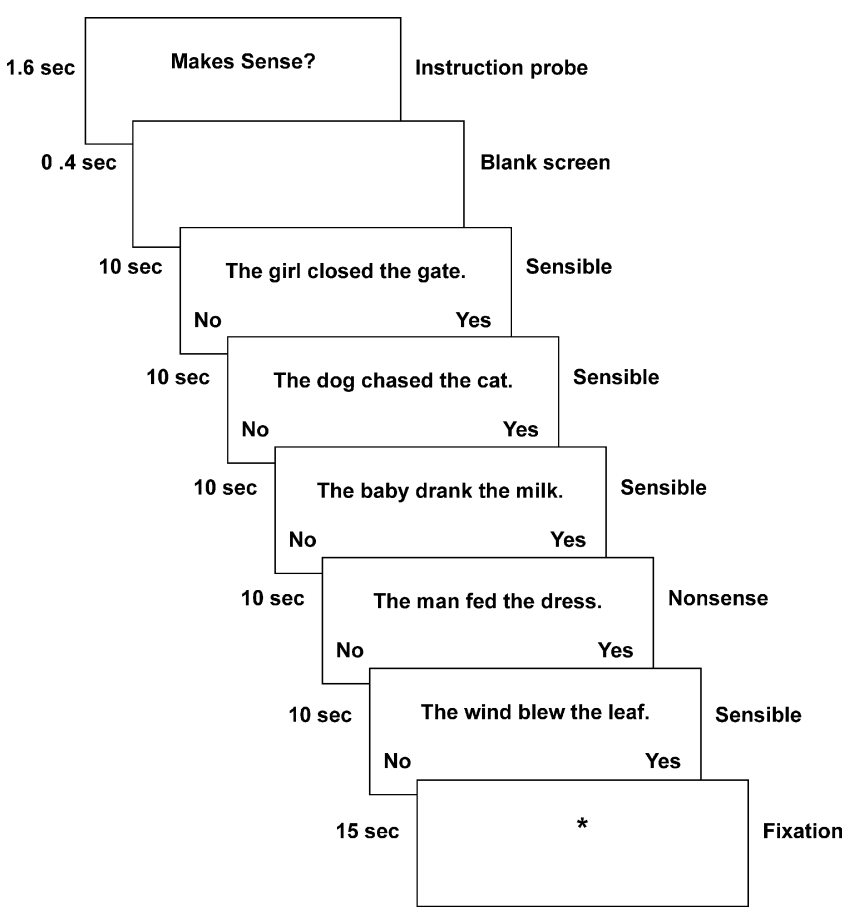

Fig. 1. Timing of a block of stimulus sentences.

of the screen as a reminder of the hand-to-response mapping. Two practice sentences, not included in the data analysis, preceded each acquisition. Head motion in the scanner was constrained using foam padding and surgical tape across the forehead.

Prior to entering the scanner, the participants were trained on two sets of practice stimuli in order to introduce them to the experimental task and setting. The first set was practiced on a computer in order to acquaint the children with the task. The second set was practiced inside a full-scale scanner simulator in order to familiarize the children with the scanner environment. Head stability training was also part of the simulation.

\section{5. fMRI acquisition}

The data were collected using a Siemens Allegra 3.0T scanner with a commercial birdcage, quadrature-drive radio-frequency head coil. Data acquisition was conducted at the Brain Imaging Research Center of Carnegie Mellon University and the University of Pittsburgh. The study was performed with a gradient-echo, echo-planar pulse sequence with $\mathrm{TR}=1000 \mathrm{~ms}, \mathrm{TE}=30 \mathrm{~ms}$ and a $60^{\circ}$ flip angle. Sixteen oblique-axial slices were imaged, and each slice was $5-\mathrm{mm}$ thick with a gap of 1-mm between slices. The oblique axial slices were positioned so that the most inferior slice was above the orbits anteriorly and passed through the fourth ventricle posteriorly. This resulted in nearly complete coverage of the cortex for most participants, with only small regions of orbito-frontal cortex and the inferior portions of the temporal poles falling outside the acquisition volume. The acquisition matrix was $64 \times 64$ with $3.125-\mathrm{mm} \times 3.125 \times 5-\mathrm{mm}$ voxels.

\section{6. $f M R I$ analyses}

The functional imaging data were analyzed using SPM99 (Wellcome Department of Cognitive Neurology, London, UK; http://www.fil.ion.ucl.ac.uk/spm). Images were corrected for slice acquisition timing, motion-corrected, normalized to the Montreal Neurological Institute (MNI) template, resampled to $2-\mathrm{mm}^{3}$ voxels, and smoothed with an 8-mm full-width at half-maximum Gaussian kernel to decrease spatial noise. High-pass filtering (cutoff $=156 \mathrm{~s}$ ) and global scaling were performed on each participant's data. Statistical analysis was conducted on individual data in each phase using the general linear model (GLM) as implemented in SPM99 (Friston et al., 1995). For each participant, the paradigm was modeled as a box-car convolved with the standard SPM99 hemodynamic response function estimate, and contrast images were generated reflecting the difference between the mean of the parameter estimates for sentence reading with that for the fixation baseline, as well as for differences between parameter estimates for the main effects of Syntactic Complexity, Sensibility, and their interaction. At the individual-participant level, a threshold of $p<.01$, corrected for multiple comparisons on the basis of random Gaussian field theory, was used to detect significant activation.

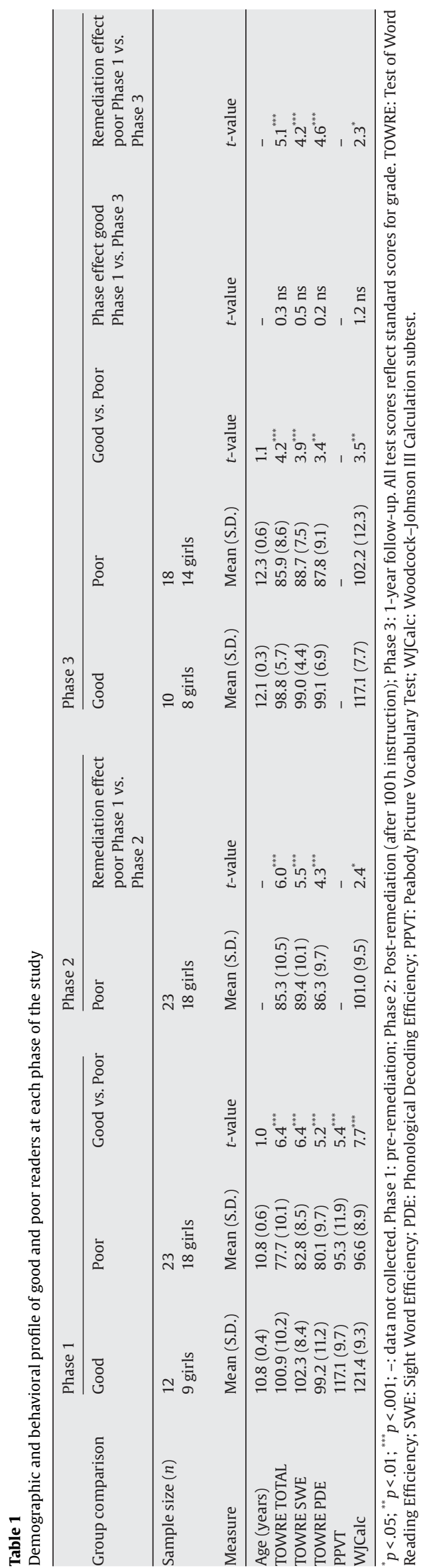


Second-level modeling of group effects, complexity and sensibility effects, and interactions among these variables was carried out within each phase of the study in SPM99 with the appropriate within-participant contrasts of parameter estimates as input to the group-level general linear model (GLM). To ensure that only voxels showing a positive difference in Sentence Reading - Fixation Baseline contrast were considered, a mask was applied that consisted of the union of voxels meeting this condition across the relevant groups and phases for the contrast of interest. An uncorrected height threshold of $p<0.002$ (two-tailed tests) and an extent threshold of 10 voxels was used for all second-level analyses. Anatomical labels for activation were determined with reference to the Automated Anatomical Labeling Toolbox (Tzourio-Mazoyer et al., 2002) and the Talairach Daemon (Lancaster et al., 2000) as implemented in AFNI software (Cox \& Hyde, 1997).

To examine group differences in cortical activation and changes in cortical activation among poor readers following remediation, two sets of analyses were performed. In the first set of analyses, 2 (Group) $\times 2$ (Syntactic Complexity) $\times 2$ (Sensibility) voxel-wise mixed ANOVAs were conducted within each phase of the study. Because there were no interesting reliable interactions between reading ability Group and either of the linguistic manipulations (i.e., Syntactic Complexity or Semantic Sensibility, see Section 3.2.1), the reporting of results focuses on simple main effects of group on brain activation during sentence reading without regard to sentence type. To explore the form of the relationship between cortical activation and reading ability across the three phases of the study in each group of readers, a set of region of interest (ROI)-based analyses was performed. In these analyses, ROIs were defined on the basis of clusters showing group differences in activation at the pre-remediation phase. The contrasts of parameter estimates (Reading minus Fixation) were extracted from each participant's first-level general linear model across all voxels in each ROI showing group differences in the first phase of the study. These contrast values were averaged for each participant, and submitted to 2 (Group) $\times 3$ (Phase) mixed effects ANOVAs, conducted separately for each of the ROIs.

\section{Results}

\subsection{Behavioral data}

\subsubsection{Standardized test scores}

Although poor readers obtained significantly lower reading scores than good readers in the pre-remediation stage (measured by the composite TOWRE scores and the Sight Word Efficiency and Phonological Decoding Efficiency subtests), following $100 \mathrm{~h}$ of remediation, the performance gap between good and poor readers was diminished by almost half on all three measures of reading ability, indicating substantial improvement in the poor readers' ability to recognize and sound out words, as shown in Table 1 . This gain was maintained at follow-up 1 year later. Scores on the Calculation subtest of the Woodcock-Johnson III also improved among poor readers between the pre- and post-remediation phases, and this improvement was maintained at follow-up (as shown in Table 1). While suggestive of a generalized effect of remediation, the size of the improvement in math skill was modest compared to the improvement in reading ability, the skill directly targeted by the intervention.

\subsubsection{Experimental task behavioral performance}

Comprehension accuracy was above $90 \%$ in both good and poor readers in each phase and for all conditions, indicating that they were semantically processing the sentences, as shown in Table 2 . A 2 (Group) $\times 3$ (Phase) $\times 2$ (Syntactic Complexity) $\times 2$ (Sensibility) mixed ANOVA on the accuracy data revealed a reliable main effect of Sensibility $(F(1,33)=9.90, p<.005)$, with sensibility judgments for sensible sentences being more accurate overall than those for nonsense sentences, as well as a reliable main effect of Syntactic Complexity $(F(1,33)=8.12, p<.01)$, with sensibility judgments more accurate for active than passive constructions. There was a reliable main effect of Phase $(F(1,59)=3.95, p<.05)$, with mean accuracy on the task significantly greater at the follow-up scan than at the pre-remediation scan or at the post-remediation scan. There was no reliable effect of reading ability Group, which is not surprising given that the task was designed to be easy enough for the poor readers to perform at a high level of accuracy. In addition, there were no reliable interactions involving any of the factors, although it should be noted that the overall high level of performance for both groups may have resulted in a ceiling effect on accuracy, thereby masking any interactions.

A similar analysis of response times to the sensibility judgment task indicated a reliable overall effect of Group $(F(1,33)=12.45$, $p<.005)$. Poor readers responded nearly $1 \mathrm{~s}$ slower to sentences than good readers. There was a substantial main effect of Phase on response times $(F(2,59)=46.22)$ resulting from a monotonic decrease in reaction times from the pre-remediation scan to the post-remediation scan, and subsequently to the follow-up scan. A reliable Group $\times$ Phase interaction $(F(2,59)=5.03, p<.01)$ indicated that this decrease in reaction time was dependent on group membership, with poor readers showing a larger decrease from pre-remediation to the follow-up $\operatorname{scan}(F(2,39)=40.92, p<.0001)$, than did good readers $(F(2,20)=9.10, p<.005)$. A main effect of Syntactic Complexity was also found $(F(1,33)=71.27, p<.0001)$, with decisions about passive constructions taking longer than decisions about active constructions. No other interactions among the four factors were significant for the response time data.

\section{2. fMRI data}

\subsubsection{Group differences in activation at the pre-remediation stage (Phase 1)}

The pre-remediation data revealed robust findings of underactivation among the poor readers (i.e., reduced activation relative to good readers) in a number of cortical areas, as indicated by a voxel-wise 2 (Group) $\times 2$ (Syntactic Complexity) $\times 2$ (Sensibility) mixed ANOVA. Poor readers displayed significant underactivation

Table 2

Good and poor readers' performance on the experimental task: mean accuracy and response times

\begin{tabular}{|c|c|c|c|c|c|c|c|c|c|c|c|c|c|}
\hline \multirow[t]{3}{*}{ Group } & & \multicolumn{4}{|c|}{ Phase 1 (pre-remediation) } & \multicolumn{4}{|c|}{ Phase 2 (post-remediation) } & \multicolumn{4}{|c|}{ Phase 3 (follow-up) } \\
\hline & & \multicolumn{2}{|l|}{ Active } & \multicolumn{2}{|l|}{ Passive } & \multicolumn{2}{|l|}{ Active } & \multicolumn{2}{|l|}{ Passive } & \multicolumn{2}{|l|}{ Active } & \multicolumn{2}{|l|}{ Passive } \\
\hline & & Sensible & Nonsense & Sensible & Nonsense & Sensible & Nonsense & Sensible & Nonsense & Sensible & Nonsense & Sensible & Nonsense \\
\hline \multicolumn{14}{|c|}{ Accuracy (percentage correct) } \\
\hline \multirow[t]{2}{*}{ Good readers } & $M$ & $98 \%$ & $100 \%$ & $97 \%$ & $98 \%$ & $99 \%$ & $98 \%$ & $92 \%$ & $98 \%$ & $99 \%$ & $100 \%$ & $97 \%$ & $99 \%$ \\
\hline & S.D. & $4 \%$ & $0 \%$ & $7 \%$ & $4 \%$ & $3 \%$ & $4 \%$ & $9 \%$ & $5 \%$ & $3 \%$ & $0 \%$ & $5 \%$ & $3 \%$ \\
\hline \multirow{2}{*}{ Poor readers } & $M$ & $94 \%$ & $97 \%$ & $92 \%$ & $91 \%$ & $92 \%$ & $96 \%$ & $92 \%$ & $96 \%$ & $97 \%$ & $99 \%$ & $92 \%$ & $99 \%$ \\
\hline & S.D. & $9 \%$ & $11 \%$ & $9 \%$ & $20 \%$ & $10 \%$ & $9 \%$ & $8 \%$ & $8 \%$ & $6 \%$ & $3 \%$ & $9 \%$ & $2 \%$ \\
\hline \multicolumn{14}{|c|}{ Reaction time (ms) } \\
\hline \multirow[t]{2}{*}{ Good readers } & $M$ & 2876 & 3014 & 3514 & 3233 & 2870 & 2722 & 3294 & 2997 & 2499 & 2482 & 2865 & 2766 \\
\hline & S.D. & 552 & 585 & 845 & 611 & 547 & 464 & 643 & 602 & 378 & 568 & 518 & 488 \\
\hline \multirow[t]{2}{*}{ Poor readers } & $M$ & 3840 & 3931 & 4578 & 4486 & 3785 & 3921 & 4422 & 4396 & 3129 & 3220 & 3787 & 3569 \\
\hline & S.D. & 950 & 820 & 1043 & 1064 & 1121 & 1345 & 1222 & 1256 & 732 & 857 & 960 & 803 \\
\hline
\end{tabular}


Table 3

Direct comparisons between good and poor readers at each phase of the study

\begin{tabular}{|c|c|c|c|c|c|c|}
\hline \multirow[t]{2}{*}{ Cortical region } & \multirow[t]{2}{*}{ BA } & \multirow[t]{2}{*}{ Cluster size } & \multirow[t]{2}{*}{ Peak $t$-value } & \multicolumn{3}{|c|}{ MNI coordinates } \\
\hline & & & & $x$ & $y$ & $z$ \\
\hline \multicolumn{7}{|l|}{ Phase 1(pre-remediation) } \\
\hline \multicolumn{7}{|l|}{ Good > Poor } \\
\hline L middle occipital, angular & 39 & 30 & 3.88 & -36 & -68 & 34 \\
\hline L inferior parietal, postcentral & 40 & 27 & 3.74 & -40 & -40 & 46 \\
\hline L superior parietal, superior occipital & $7 / 19$ & 41 & 4.52 & -20 & -68 & 42 \\
\hline L middle frontal & 8 & 10 & 4.24 & -30 & 24 & 56 \\
\hline $\mathrm{R}$ inferior parietal, supramarginal & 40 & 15 & 3.74 & 40 & -44 & 44 \\
\hline R supramarginal, inferior parietal & 40 & 13 & 3.72 & 48 & -36 & 44 \\
\hline \multicolumn{7}{|l|}{ Poor $>$ Good } \\
\hline Anterior SMA & 6 & 101 & 4.65 & 0 & 10 & 52 \\
\hline Posterior SMA & 6 & 18 & 3.94 & 2 & -4 & 72 \\
\hline \multicolumn{7}{|l|}{ Phase 2 (post-remediation) } \\
\hline \multicolumn{7}{|l|}{ Good $>$ Poor } \\
\hline L superior parietal, superior occipital & 7 & 19 & 3.71 & -18 & -70 & 42 \\
\hline L middle frontal & 8 & 18 & 4.46 & -26 & 24 & 56 \\
\hline \multicolumn{7}{|l|}{ Poor $>$ Good } \\
\hline L putamen & & 116 & 4.15 & -22 & 14 & 0 \\
\hline L putamen & & 12 & 3.58 & -16 & -2 & 10 \\
\hline $\mathrm{R}$ insula, inferior frontal & 45 & 92 & 4.32 & 36 & 24 & 4 \\
\hline \multicolumn{7}{|l|}{ Phase 3(follow-up) } \\
\hline \multicolumn{7}{|l|}{ Good > Poor } \\
\hline L cuneus, superior occipital & 19 & 10 & 3.83 & -6 & -90 & 26 \\
\hline \multicolumn{7}{|l|}{ Poor $>$ Good } \\
\hline L postcentral gyrus & 2 & 271 & 4.66 & -28 & -22 & 34 \\
\hline L insula, putamen & & 50 & 4.05 & -24 & 20 & 6 \\
\hline L insula & & 15 & 3.87 & -38 & 8 & -10 \\
\hline L superior frontal, cingulate & 6 & 89 & 4.41 & -20 & -2 & 46 \\
\hline $\mathrm{L}$ anterior superior frontal & 9 & 36 & 4.58 & -14 & 46 & 26 \\
\hline L anterior cingulate & 32 & 150 & 5.21 & -16 & 30 & 20 \\
\hline $\mathrm{L}$ anterior cingulate & 32 & 31 & 4.41 & -18 & 46 & 0 \\
\hline L middle cingulate & 24 & 17 & 3.98 & -14 & -10 & 36 \\
\hline L thalamus & & 59 & 4.50 & -12 & -8 & 0 \\
\hline L thalamus & & 14 & 3.99 & -22 & -24 & 2 \\
\hline L cerebellum, vermis & & 10 & 4.32 & -4 & -56 & -6 \\
\hline R postcentral gyrus & 3 & 67 & 4.63 & 24 & -36 & 52 \\
\hline $\mathrm{R}$ putamen, insula & & 50 & 4.48 & 30 & 12 & -6 \\
\hline R superior frontal, SMA & 6 & 17 & 4.30 & 18 & -16 & 60 \\
\hline $\mathrm{R}$ anterior cingulate & 24 & 29 & 4.52 & 10 & 30 & 6 \\
\hline $\mathrm{R}$ posterior cingulate & 23 & 15 & 4.51 & 12 & -34 & 28 \\
\hline R precuneus & & 30 & 4.09 & 22 & -54 & 28 \\
\hline R cerebellum, vermis & & 24 & 4.13 & 4 & -70 & -34 \\
\hline
\end{tabular}

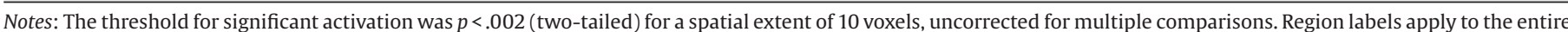

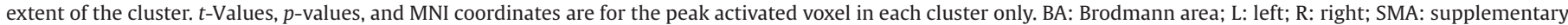
motor area.

in parietal and frontal areas. As shown in Table 3 and Fig. 2 (upper panel), in the left hemisphere these differences appeared in the middle occipital gyrus extending into the angular gyrus (BA 39), in the inferior parietal lobule bordering the postcentral gyrus (BA 40 ), in the superior parietal lobule extending into the superior and middle occipital gyri (BA 7), and in the middle frontal gyrus (BA 8 ). In the right hemisphere, poor readers showed less activation than good readers in the right inferior parietal lobule projecting into the supramarginal gyrus (BA 40). In one region, the supplementary motor area (BA 6), poor readers showed greater activation than good readers bilaterally.

No group differences in activation were found in occipitotemporal areas at the pre-remediation phase. Inspection of the activation maps within each of the groups for the contrast of sentence reading with the fixation indicated that although each group showed strong occipital activation, neither group showed activation extending anteriorly into occipito-temporal cortex.

There were no areas that showed a reliable interaction between reading ability Group and either the Syntactic Complexity or Sen- sibility of the sentences, nor were there any areas that showed a three-way interaction in the pre-remediation phase. There were, however, areas that showed main effects of each of the linguistic manipulations across the entire sample of children. For example passive sentences produced greater activation than active sentences in a number of occipital regions. Because the focus of the study was on identifying group differences in activation and on assessing the effect of intensive remediation on reducing these differences, the remaining analyses collapse across levels of Syntactic Complexity and Sensibility.

In summary, the pre-remediation measurements indicate underactivation in the poor readers, relative to the good readers, in bilateral parietal areas. There were no clear differential impacts of the linguistic manipulations on the two reading groups.

\subsubsection{Group differences in activation at the immediate post-remediation stage (Phase 2)}

Following reading remediation, there was a reduction in the number of parietal regions showing reliable underactivation among 
Good > Poor at Phase 1 (Pre-remediation)
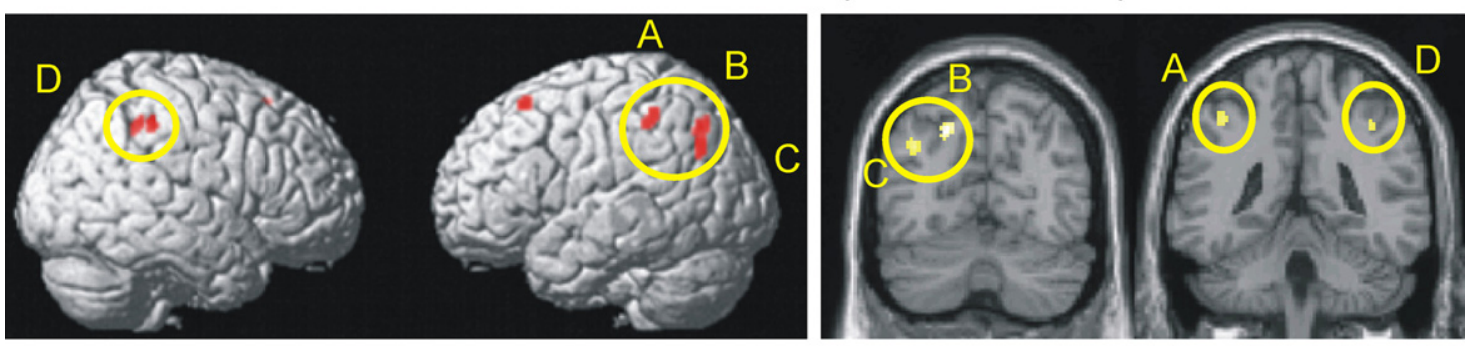

Good > Poor at Phase 2 (Immediate Post-remediation)
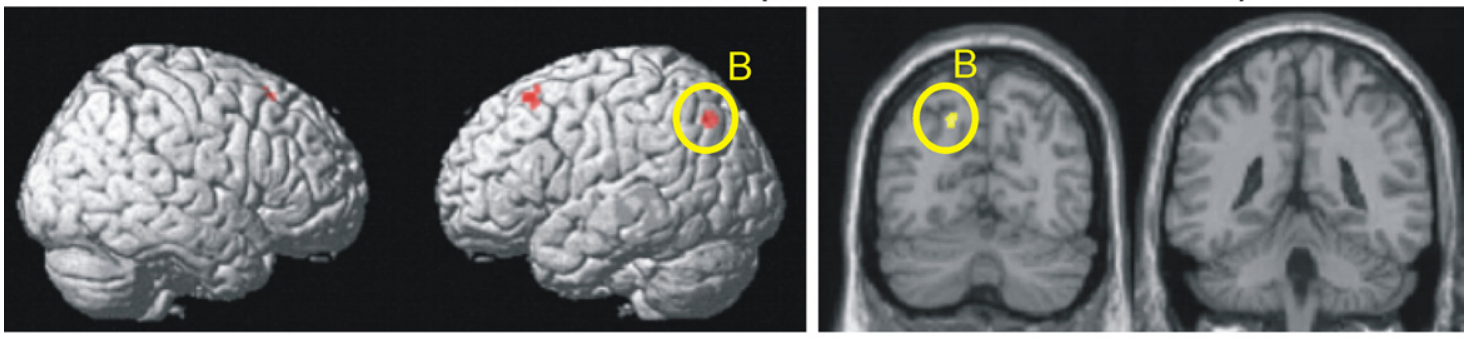

Good > Poor at Phase 3 (One-year Follow-up)
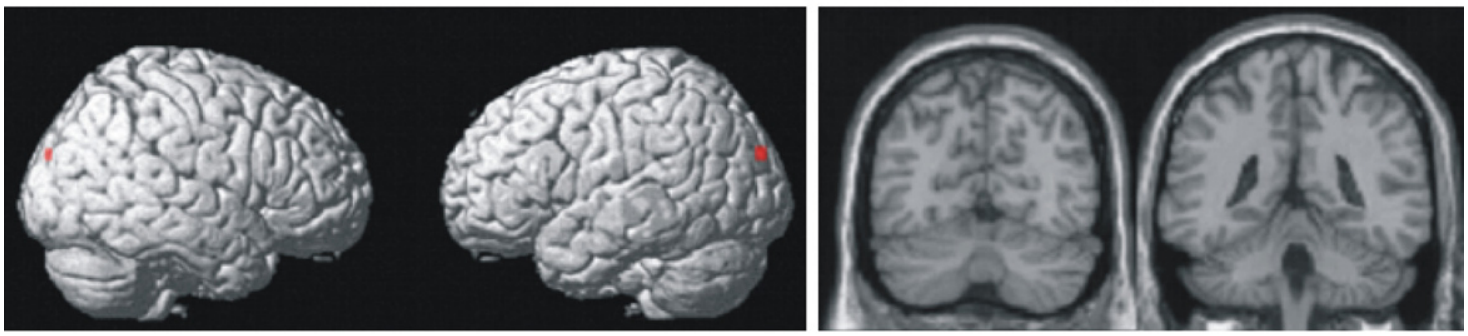

$A=$ left inferior parietal, $B=$ left superior parietal, $C=$ left angular gyrus, $D=$ right inferior parietal

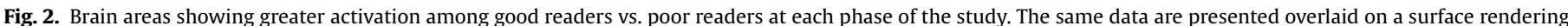

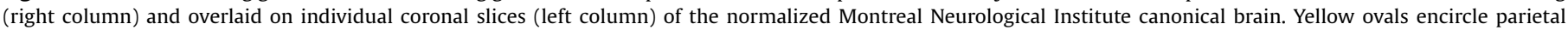
activation.

poor readers and a reduction in the size of the regions that continued to show underactivation, as indicated by an analysis of the main effect of reading ability Group, shown in Table 3 and Fig. 2 (middle panel). By Phase 2, the areas that continued to show less activation among poor readers than good readers included the left superior parietal lobule (BA 7) and the left middle frontal gyrus (BA 8). In the reverse contrast (Poor $>$ Good), poor readers showed greater activation than good readers bilaterally in the inferior frontal cortex (right insula and right inferior frontal gyrus (BA 45), and two clusters in the left putamen).

\subsubsection{Group differences in activation at the 1-year follow-up stage (Phase 3)}

The number of brain regions showing less activation among poor readers than good readers decreased further at the time of the follow-up at 1 year post-remediation to only one region, the left cuneus, bordering the superior occipital gyrus (BA 19), as shown in Table 3 and Fig. 2 (lower panel). In contrast poor readers showed more activation than good readers across the medial frontal cortex, including the left and right superior frontal and anterior cingulate gyri (BA 9 and BA 32), the left middle cingulate gyrus (BA 24), and the right posterior cingulate gyrus (BA 23). Other regions showing more activation among poor readers in Phase 3 included inferior frontal clusters in the left and right putamen extending into the insula, as well as clusters in the left thalamus, the right precuneus and postcentral gyrus, and the left and right vermis of the cerebellum.

\subsubsection{Main analyses of changes in parietal activation}

ROI analyses (as described in Section 2) were used to assess the relationships among parietal activation, reading ability, and time. In these analyses, measures of cortical activation in each phase were extracted for good and poor readers in areas showing group differences in Phase 1: the left angular gyrus, the left inferior parietal lobule, the left superior parietal lobule, and the right inferior parietal lobule. These mean parameter estimates for left and right parietal clusters were submitted to separate 2 (Group) $\times 3$ (Phase) mixed ANOVAs. Additional within-group ANOVAs examined the effects of phase within each reader group for each ROI. By virtue of the procedure for defining the ROIs, each of them showed more activation for the good than the poor readers (left angular gyrus, the left inferior parietal lobule, the left superior parietal lobule, and the right inferior parietal lobule, with $F$-ratios of $F(1,33)=11.81$, $p=.002, F(1,33)=5.38, p=.03, F(1,33)=13.47, p=.001$, and $F(1$, $33)=4.34, p=.05$, respectively). The ROI analyses revealed significant Group $\times$ Phase interactions in each ROI, [left angular gyrus: $F(2,59)=5.51, p=.007$, left inferior parietal lobule: $F(2,59)=5.68$, $p=.006$, left superior parietal lobule: $F(2,59)=4.72, p=.01$, and right inferior parietal lobule: $F(2,59)=6.06, p=.004]$. These findings indicate that the phase-related change in each of these cortical areas 

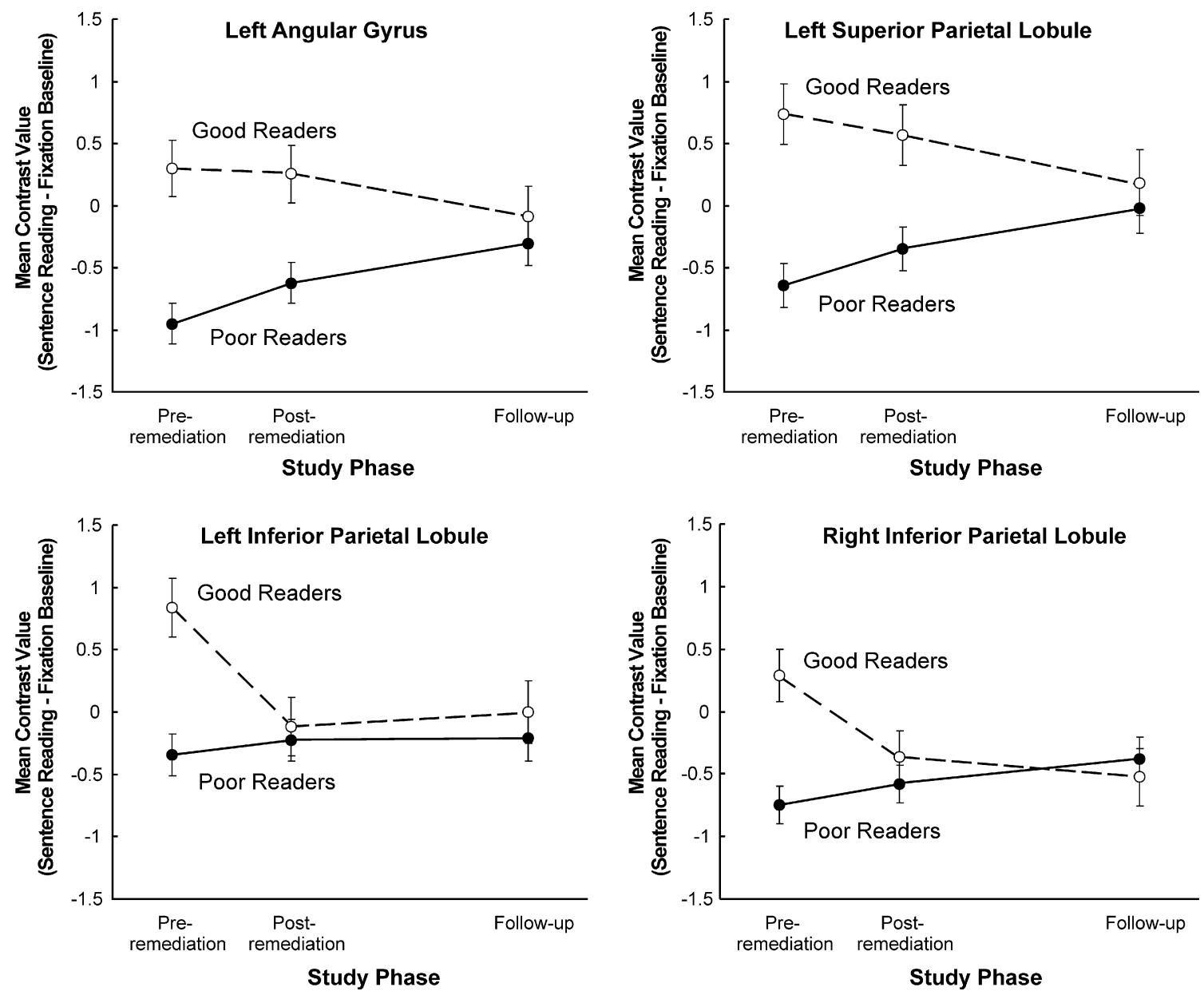

Fig. 3. Pattern of change in activation across the three phases for each reading ability group in parietal regions of interest.

was different for the two groups of readers. Within-group ANOVAs revealed significant increases of activation across phases among poor readers in the left angular gyrus, $F(2,39)=5.29, p=.009$, and the left superior parietal lobule, $F(2,39)=3.29, p=.05$. Among good readers, there were no significant phase-related activation changes in these regions. These findings indicate that the major impact of reading remediation among poor readers occurs in the left parietal lobe, with the most significant effect appearing in the left angular gyrus, as shown in Fig. 3.

There were other regions in which only the good readers' activation changed (in terms of decreasing activation across phases) possibly reflecting an efficiency gain. In the left and right inferior parietal lobules, activation did not change significantly over time among poor readers. However, main effects of Phase were found for good readers in these regions, [left inferior parietal: $F(2,20)=6.39$, $p<.007$, right inferior parietal: $F(2,20)=6.39, p<.02$ ]. Activation in these regions decreased significantly among good readers in Phase 2, and remained stable in Phase 3 (see Fig. 3).

Almost all of the poor readers showed increased activation in parietal areas and also almost all showed an increase in their TOWRE scores, both for the Phonological Decoding Efficiency subtest and the Sight Word Efficiency subtest, with a modest, nonsignificant correlation of $r=.17$ between the change in SWE and change in activation in the left angular gyrus region of interest, and an $r=.04$ between change in PDE and change in activation in the same region. Fig. 4 depicts the relationship between change in the total TOWRE measure between the pre-remediation and follow-up phases, and the change in activation for individual poor readers in the left angular gyrus. Note that the change in activation level could involve changes in other reading-related processes besides those tapped by the TOWRE.

Here and elsewhere our analyses have focused on the combined TOWRE PDE and SWE scores, because the subtests have not provided distinguishing insights. For example, were the data in Fig. 4 to be separated into separate graphs for PDE and SWE scores, the two graphs would look remarkably similar to each other. The combined score appears to provide some advantage due to averaging

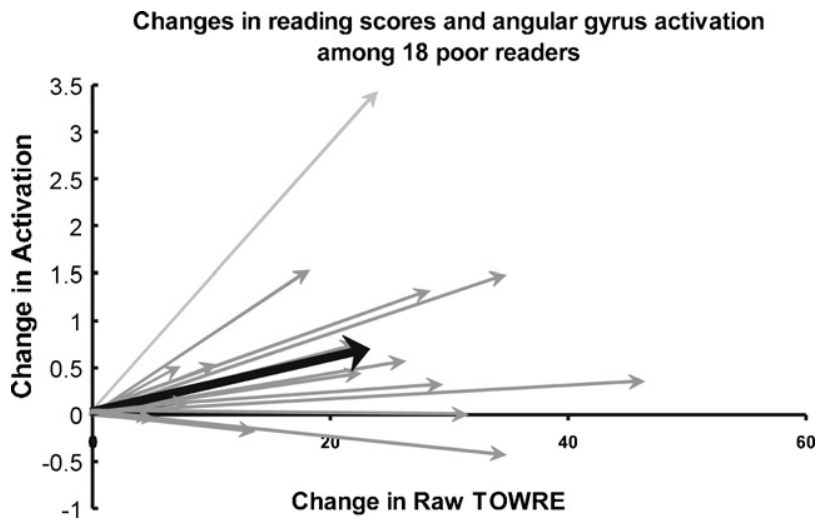

Fig. 4. The relationship between changes in activation in the left angular gyrus and changes in reading ability between Phases 1 and 3 among individual poor readers. Arrow in bold depicts the mean coordinates for TOWRE score and activation change. 
over noise. More generally, the TOWRE subtests do not reveal a differential effect of the remedial instruction, perhaps reflecting the fact that the instructional programs would be expected to enhance performance in both subtests.

To summarize, the findings indicate that reading remediation resulted in changes in reading ability and cortical function among poor readers. Additional voxel-wise analyses of Group $\times$ Phase interactions yielded converging results, and they are reported in Appendix B due to their length. A consistent finding emerging across analyses was that with remedial reading instruction, there was a normalization of activation among poor readers in left parietal areas including the angular gyrus and the superior parietal lobe.

\section{Discussion}

This study determined, for the first time, how remedial instruction modulates cortical function when struggling readers read sentences for comprehension. The central finding was that left parietal areas that showed underactivation prior to treatment, exhibited a substantial (and statistically significant) increase in activation among poor readers following $100 \mathrm{~h}$ of intensive remedial intervention. Moreover, there were corresponding gains on behavioral measures of reading. Furthermore, the activation in the left parietal region continued to increase 1 year after the intervention had ended, resulting in a normalization of activation in two regions associated with reading, the left angular gyrus and the left superior parietal lobule. This result indicates that effective reading remediation has both immediate and more enduring effects on the development of the cortical network underlying reading. The results yield new insight into the neural effects of successful remedial treatment in the context of sentence comprehension.

The finding that the left parietal region was both the central locus of dysfunction among poor readers during sentence comprehension, as well as the main area of change following remediation, aligns with earlier work that focused on word-level processing among dyslexic children (Aylward et al., 2003; Shaywitz et al., 2004; Simos et al., 2002; Temple et al., 2003) and dyslexic adults (Eden et al., 2004). The new converging evidence implicates this area as a main site of intervention-related change across different ages and reading tasks. We speculate that changes in the phonological processes associated with this area are centrally involved in the improved reading performance in poor readers.

\subsection{The effects of remediation on parietal activation}

In the present study, the most dramatic change in cortical activation among poor readers occurred in the left angular gyrus (BA 39). This structure is considered to be pivotal in the mapping between phonological and orthographic representations of words (Booth et al., 2003, 2004; Pugh, Mencl, Shaywitz, et al., 2000; Shaywitz et al., 2002), as well as for the integration of these word forms with their semantic representations (Booth et al., 2003). Studies of normal and atypical readers are compatible with that interpretation. A recurrent finding in neuroimaging studies of reading impairment is of underactivation of the left angular gyrus among dyslexic readers, particularly on tasks that make explicit demands on phonological assembly (Pugh, Mencl, Jenner, et al., 2000; Pugh, Mencl, Shaywitz, et al., 2000). Other work has found significantly greater activation in the left angular gyrus among adults as compared to children during tasks requiring conversion between phonology and orthography (Booth et al., 2004).

Because word decoding is the primary bottleneck in the acquisition of skilled reading, it is not surprising to find underactivation among this population in brain areas associated with converting print to sound, even when reading sentences for comprehension. Children who have a school history of reading problems tend to have particular difficulty reading words, both in isolation and in context (Gayan \& Olson, 2001). Instructional treatments that target word-decoding skills, such as those used in the present study, may induce characteristic changes in these areas of the brain.

While it is very likely that the left angular gyrus is involved in word-level processing, it could also subserve additional phonologically related operations that are relevant for sentence comprehension. One possibility is that the left angular gyrus operates in conjunction with other parieto-temporal structures to store and integrate multiple elements of linguistic information in a sound-based verbal working memory. According to this conceptualization, the left angular gyrus and surrounding parietotemporal cortex serve a broader function in reading, playing a role in sentence-level assembly as well as word-level assembly (Meyler et al., 2007). In this view, problems associated with verbal working memory may appear at different levels of analysis: from mapping print to sound at the level of words, to the temporary storage and integration of sound-based word information at the sentence level. The extent to which individual parieto-temporal areas are activated may depend, in part, on the demands of the reading task and the skill of the reader.

Higher-level processes reliant on verbal working memory could also involve operations such as syntactic parsing and semantic integration (Keller et al., 2001). While the design of the present study may not have had sufficient power to detect these processes, other work has shown that that the left angular gyrus/BA 39 is sensitive to syntactic complexity manipulations (Constable et al., 2004; Humphries, Binder, Medler, \& Liebenthal, 2006), particularly in the case of printed sentences (Constable et al., 2004). The response of this region also increases with higher semantic processing demands, as indicated in a study of auditory sentence comprehension comparing semantically congruent, semantically incongruent, and pseudoword sentences (Humphries et al., 2006). Thus, the left angular gyrus and adjacent structures may be important not only to processing and maintaining phonological information in words and sentences, but also to other higher-level reading operations such as processing the grammatical identity and order of words, and the relationships between the meanings of individual words. Remedial instruction may have enhanced these functions among poor readers.

In the present study, the left superior parietal lobule (BA 7) was a second region that showed increased activation among poor readers following remedial treatment. The superior parietal lobule has been linked to a number of cognitive processes, including verbal short-term memory (Clark \& Wagner, 2003; Cutting et al., 2006; Davachi, Marril, \& Wagner, 2001; Honey, Bullmore, \& Sharma, 2000), attentional control, cross-modal integration (Collette et al., 2005; Saito et al., 2005; Shomstein \& Yantis, 2004, 2006), and mental imagery during reading (Just, Newman, Keller, McEleney, \& Carpenter, 2004). While we cannot ascertain the precise function of this region in sentence reading on the basis of the present study, higher activation among poor readers following remediation could reflect improvement in one or more of the above processes.

No change in activation was found in the left and right inferior parietal lobules (BA 40) among poor readers, two areas that showed a progressive reduction in activation among good readers during the period of the study. Among poor readers, activation in these areas remained persistently low. Similar findings were reported by Hoeft et al. (2006), who found that dyslexic children showed less activation than chronological age-matched controls and readingmatched controls in the left and right inferior parietal lobules when performing a word rhyming task. In that study however, activation in these regions increased among normal readers with age, 
suggesting that the extent to which these areas are involved in reading may be task related. Like BA 39 and BA 7, BA 40 is associated with verbal short-term memory (Chen \& Desmond, 2005; Davachi et al., 2001; Woodward et al., 2006), such that decreasing activation among good readers could reflect a reduction in verbal memory load as the result of familiarity and experience with the stimuli. The reason for the consistently low level of involvement of the inferior parietal lobules among poor readers is not clear, but could be indicative of an atypical pattern of skill development. Possibly, poor readers may fail to fully utilize the processing capacities of the parieto-temporal regions.

\subsection{Absence of reading ability or remediation effects in occipito-temporal areas}

Conspicuously absent in the present data is any hint of an effect of either reading ability or intensive remediation on activation in left occipito-temporal areas. As noted in the introduction, some previous studies have found lower activation among poorer readers than better readers in this age range in an area of the left midfusiform gyrus (Aylward et al., 2003; Hoeft et al., 2007; Shaywitz et al., 2002, 2004), a location consistent with the putative visual word form area (VWFA) thought to provide for relatively specialized and automatic processing of the visual features of words in the native language of adult skilled readers (Cohen et al., 2000, 2002). In addition, there are previous reports of increases in activation in this left occipito-temporal region following word-level remediation treatments in poor readers (Aylward et al., 2003; Shaywitz et al., 2004). In contrast to the present study, these earlier neuroimaging studies of children with poor reading ability used tasks that focused on phonology (of individual words) rather than sentence comprehension, likely increasing the involvement of the processes underpinned by occipito-temporal cortex. The present study did not find group differences in activation or effects of remediation in this occipito-temporal region. Moreover, the present study did not find activation within either group in this area for the contrast between sentence reading and the fixation baseline in any phase of the study, suggesting that this area plays a smaller role in sentence comprehension than in various phonological judgment tasks. Kronbichler et al. (2006) failed to find occipito-temporal activation in adolescent dyslexic readers when a sentence comprehension task was contrasted with a low-level visual baseline, but did find such activation in controls, although this group difference was not reliable in a voxel-based analysis. It is possible that the choice of baseline is critical for detecting activation in the VWFA, as most studies reporting activation in this area have used a low-level visual control task. Interestingly, we also failed to detect within-group activation or group differences in activation in occipito-temporal cortex in a study contrasting a word-level, visually presented rhyme judgment task with a fixation baseline in a sample of participants that largely overlapped with the present sample (Hoeft et al., 2006). Additional research will be necessary to determine the precise reading conditions that give rise to (1) occipito-temporal activation in general, (2) reading ability group differences and (3) effects of reading remediation. We speculate that those conditions will involve a complex interaction of methodological factors including the experimental task, the baseline task, and the age of the participants.

\subsection{Areas of overactivation among poor readers following remediation}

Evidence of overactivation was found in the inferior frontal and medial frontal cortices among poor readers following remediation, indicating possible areas of compensatory activation. In the present study, heightened activity (relative to the good readers) was found in the right inferior frontal cortex immediately following intensive remedial instruction. Enhanced (left and right) inferior frontal activation following remediation had been noted in several previous reports of word-level processing (see Shaywitz, Lyon, \& Shaywitz, 2006, for a review). Activation changes in the right hemisphere homologues of language areas might be due to a compensatory response in non-dominant cortical regions (Temple et al., 2003). Overactivation among the poor readers was also observed in the medial frontal cortex, in the right and left superior frontal and anterior cingulate gyri, 1 year post-instruction. Both medial frontal areas have been associated with attentional control, performance monitoring, and error detection (Miller \& Cohen, 2001; Nebel et al., 2005). Thus the poor readers' medial and superior frontal overactivation may reflect the recruitment of additional executive resources, possibly indicating the use of a more effortful and attentionally guided reading strategy than the one used by good readers.

In general, findings on the location and extent of compensatory activation have not been consistent across investigations. The reason for the differences among studies is not yet known, although it has been suggested that some of the variation may be due to the age of the population examined, or to the stage of the recovery process (Eden et al., 2004), to differential task demands, or to differences in the types of remediation. Further exploration of these issues may elucidate the contribution of different variables to brain responses to remedial treatment.

\subsection{Mechanisms of neural change in the development of reading}

The different developmental trends observed among good and poor readers in the left angular gyrus and in the left superior parietal lobule could reflect different stages in the acquisition of reading. An initial increase in activation in these areas may characterize an earlier stage of learning to read. This rise may be followed by a stabilization of activation as reading skills become more consolidated. It is also possible that as reading skills become more automatic, activation in these regions will subsequently decrease, as shown in other research on the cortical effects of practice (e.g. Chein \& Schneider, 2005). Thus, there may be a systematic nonmonotonic change in the activation level of a cortical area as reading ability develops, which can be thought of as an inverted-U-shaped function relating activation level to time, over a span of a few years. This suggestion is compatible with other studies of brain changes during learning, which report an inverted U-shaped learning curve associated with skill development over shorter time spans, such as days (see Little \& Thulborn, 2006, for a review). Little and Thulborn have interpreted the initial activation increase in a task-related area as reflecting increasing recruitment of neural tissue during the earlier learning stage, and the later decrease in activation as reflecting increased automaticity and elimination of irrelevant processes.

We interpret the progressive increase in left parietal activation among poor readers over time as the neural basis of the improved reading ability. While we cannot definitively conclude from our study that the neural change was caused by the remedial treatment, this interpretation is consistent with the observed improvement in reading ability in our longitudinal within-group comparison, as well as the pre- and post-test comparison between groups. The interpretation is also consistent with earlier research showing remediation-related activation increases among impaired readers in the same regions in word-level studies.

An alternative interpretation of the new findings that we disfavor is that the observed increase in parietal activation among poor readers was simply due to the effects of maturation. However, it seems unlikely that the poor readers happened to become better readers and with more parietal activation just when the reading 
intervention occurred. While it is possible that the poor readers were experiencing a developmental delay that was resolved over time, there is some evidence suggesting that this was not the case. Our sample initially included a subset of poor readers who did not receive remedial treatment, but continued to participate in the reading programs already in place at their schools. Although the attrition rate was very high in this group (hindering a full-fledged group comparison), there remained a small group of six children in the study through follow-up. A comparison of the cortical activation at pre-test and follow-up indicated no significant change in cortical activation over time among these children in the critical parietal areas. While the small sample size limits the statistical power of this analysis, the results are nevertheless suggestive. Additional research including a larger sample of untreated children, or children receiving different types of remedial treatments, would permit stronger conclusions about the neural effects of reading remediation.

\section{Conclusions}

Several findings in this study have important implications for current understanding of the nature of reading difficulty, and of the neurobiological basis of successful remedial intervention. First, this study demonstrated that intensive reading intervention leads to significant and enduring changes in brain function among poor readers, which correspond to demonstrable gains in reading ability. Second, the area of cortical change occurring during sentence comprehension was the same area that has been associated with reading remediation in earlier word-level studies, namely the left parietal cortex. These converging findings support the view that reading intervention promotes change in the neural systems that support skilled reading, and points to a similarity of impact across higher- and lower-level reading tasks.

Another implication of the study is that remedial treatment may similarly alter neural circuitry among poor readers regardless of their level of impairment. The poor readers in this study spanned a range of reading ability. An IQ-reading ability discrepancy was not used as a criterion for inclusion, and the sample included both less severely and more severely impaired readers, including children who would be considered dyslexic. Despite this variation among the poor readers, our findings were entirely consistent with investigations using more stringent diagnostic criteria for reading disability. Our results indicate that reading ability and disability fall along a continuum, with severe reading problems, or dyslexia, representing the lower tail (Shaywitz, Escobar, Shaywitz, Fletcher, \& Makuch, 1992; Vellutino et al., 2004). This position is also compatible with findings from behavioral research indicating that criteria often used to define dyslexic readers (such as IQ-reading ability discrepancy) are not related to poor readers' phonological processing deficits or to their response to remediation efforts (Gayan \& Olson, 2001; Stanovich \& Siegal, 1994; Vellutino, Scanlon, \& Lyon, 2000). The question of continuity of function in the brain-behavior relationship remains to be further explored, although initial evidence supports this view (e.g. Hampson et al., 2006; Meyler et al., 2007; Shaywitz et al., 2002). The answer could have relevance for our understanding of the nature of reading problems, and for public policy regarding their identification and treatment.

\section{Acknowledgements}

This research was supported by grants from the R.K. Mellon Foundation, the National Institute of Mental Health (Grant MH029617), and the William and Flora Hewlett Foundation. Participants were recruited through the Power4Kids program, which is a public-private partnership including the Haan Foundation for Children; Institute of Education Sciences, U.S. Department of Education; Heinz Endowments; Smith Richardson Foundation; W.K. Kellogg Foundation; Grable Foundation; Rockefeller Foundation; Ambrose Monell Foundation; Raymond Foundation; and Barksdale Reading Institute. For a full description of this project, see http://www.ed.gov/rschstat/eval/disadv/title1 interimreport/index. html. We thank Cindy Haan and Joe Torgesen for leadership of the Power4Kids program. We also thank Donna Durno, Rosanne Javorsky, and the Allegheny Intermediate Unit for their central coordinating efforts throughout the project.

\section{Appendix A. Description of remediation programs}

In order for the programs to fit the broad classifications of word-level vs. word-level plus comprehension level, the Corrective Reading and Wilson Reading programs were modified to include only the components involving word-level instruction. Corrective Reading includes systematic, explicit, scripted instructional procedures designed to focus attention on critical components of word identification and to increase the rate and fluency of word identification through the oral reading of stories. Additional procedures of the program that focus on higher-level comprehension were not included in present study. The Wilson Reading program also provides a systematic, structured instructional sequence, but incorporates auditory, tactile, and kinesthetic methods for training students in letter sound identification skills. Additional elements of the program that focus on vocabulary and comprehension skills were not included in remedial instruction received by the poor readers. The Spell Read Phonological Auditory Training program consists of systematic lessons that first provide explicit instruction in phonics and phoneme awareness and then allow students to apply these skills to more naturalistic reading and writing tasks. Because of this, the program was originally included in the Power4Kids project as an example of an intervention providing both word-level and higher-level comprehension instruction. However, an analysis of the time actually spent on each of the activities of the program during the actual intensive remediation indicated that the program was more properly classified as a word-level instructional approach. In contrast to the other three programs, Failure Free Reading does not focus on phonemic decoding skills, but rather provides explicit computer-based, workbook-based, and teacher-led instruction on sight word reading vocabulary acquisition, fluency, and comprehension skills. Time by activity analyses of actual in-classroom instruction indicated that the program was indeed properly classified as one that provided both word-level and comprehension level instruction.

These four different reading instructions were provided to randomly selected poor readers over the course of 6 months. By the conclusion of the intervention, all children in the poor reading group had received approximately $100 \mathrm{~h}$ of intensive reading instruction. In the present study, the number of participants in each program was small (Corrective, $n=5$; Wilson, $n=5$; Spell Read, $n=7$; and Failure Free, $n=6$ ), and no significant differences were observed in terms of the behavioral or the neurophysiological outcomes of the four instructional approaches. Furthermore, the large-scale behavioral study that included a total of 407 fifth-grade children (Corrective, $n=86$; Wilson, $n=91$, Spell Read, $n=104$; Failure Free, $n=126$ ), found no reliable differences in impact among the four programs on reading ability measured by TOWRE scores (Torgesen et al., 2006). Given the small sample size in the fMRI study and these failures to find behavioral differences among the four programs, the data from the four instruction groups are combined for all analyses presented here. 
Table B.1

Voxel-wise analyses of 2 (Group) $\times 2$ (Phase) simple interactions

\begin{tabular}{lccrrr}
\hline Cortical region & Cluster size & Peak F-value & \multicolumn{2}{c}{ MNI coordinates } \\
\cline { 4 - 6 } & & & $x$ & $y$ & $z$ \\
\hline Pre-remediation vs. post-remediation & & & & & \\
$\quad$ L inferior parietal & 21 & 13.90 & -40 & -40 & 44 \\
L putamen & 11 & 14.78 & -22 & 14 & 2 \\
R middle frontal gyrus & 21 & 15.30 & 30 & 56 & -2 \\
R thalamus & 37 & 18.03 & 14 & -6 & 10 \\
L cerebellum & 13 & 16.53 & -32 & -48 & -26 \\
& & & & & \\
Pre-remediation vs. follow-up & 12 & 14.20 & -32 & -56 & 26 \\
L angular gyrus & 20 & 18.66 & -58 & -22 & 24 \\
L supramarginal gyrus & 65 & 21.82 & 46 & -38 & 42 \\
R supramarginal gyrus & 15 & 15.10 & -12 & -46 & 14 \\
L precuneus & 32 & 16.68 & -22 & 18 & 4 \\
L putamen & 10 & 17.20 & -30 & 26 & 40 \\
L middle frontal gyrus & 11 & 17.92 & 16 & 20 & 62 \\
R superior frontal gyrus & 11 & 13.36 & 16 & -10 & 44 \\
R middle cingulate gyrus & 11 & 19.11 & 20 & -94 & -14 \\
R lingual gyrus & 24 & & & & \\
\hline
\end{tabular}

Notes: The threshold for significant activation was $p<.002$ (two-tailed) for a spatial extent of 10 voxels, uncorrected for multiple comparisons. Region labels, $F$-values, and MNI coordinates are for the peak activated voxel in each cluster. The activated clusters may extend beyond the boundaries of the region labels. AAL labeling (Tzourio-Mazoyer et al., 2002). MNI: Montreal Neurological Institute.

\section{Appendix B. Voxel-wise analyses of group by phase interactions}

Separate 2 (Phase) $\times 2$ (Group) voxel-wise mixed ANOVAs comparing the pre- and post-remediation phases, and the preremediation and follow-up phases of the study, confirmed that the same regions of the left and right parietal where poor readers showed underactivation in the pre-remediation phase, also showed changes in the group difference between phases of the study. A complete list of areas showing such interactions is provided in Table B.1, and here we explore the form of these interactions by considering the simple effects of Group within each of the phases and the simple effects of Phase within each of the groups.
When the first two phases were considered, five regions showed a simple Group $\times$ Phase interaction, as shown in Table B.1. Notably, a cluster in the left inferior parietal lobule showing such an interaction was nearly identical to the cluster where a group difference had been found at the pre-remediation scan (see Fig. B.1), and tests of the simple main effect of Group within each Phase indicated a reliable Group effect prior to remediation at the peak voxel in this cluster $(F(1,33)=13.11, p<.001)$ but not at the scan immediately following remediation $(F(1,33)=0.16$, ns). Tests of the simple main effect of phase within each group at this location indicated a marginal decrease in activation among good readers $(F(1,11)=14.17$, $p=.003)$ and a non-significant increase in activation among poor readers $(F(1,22)=1.62$, ns). In contrast, a cluster in the left putamen showed the opposite pattern. At the pre-remediation scan there was no difference in activation in the peak voxel in this cluster $(F(1$, $33)=0.07$, ns), but at the immediate post-remediation scan there was a reliable effect of $\operatorname{Group}(F(1,33)=15.63, p<.0005)$, with poor readers activating this region for the sentence reading task more than good readers. Tests of the simple effect of phase within each reading group indicated a reliable increase in activation between the pre- and post-remediation phases among poor readers $(F(1$, $22)=15.02, p<.001)$, and a trend toward a decrease among good readers $(F(1,11)=3.72, p=.08)$. The remaining clusters reported in the upper portion of Table B.1 failed to show significant simple main effects of group at either scan, indicating that the reliable interactions resulted from differential changes in activation with time. In the right thalamus, good readers showed a reliable decrease in activation with time $(F(1,11)=24.27)$, but poor readers did not $(F(1$, $22)=1.19$, ns). In the left cerebellum poor readers showed a reliable decrease in activation between phases $(F(1,22)=16.45, p<.0005)$, but good readers did not $(F(1,11)=4.10$, ns). In the right middle frontal gyrus good readers showed a trend toward decreased activation over time $(F(1,11)=12.34, p<.005)$ but poor readers showed no change $(F(1,22)=1.75)$.

The simple Group $\times$ Phase interaction involving the pairwise comparison of the pre-remediation phase with the follow-up phase may reveal areas where the difference in activation between the

Decreases in Group Difference between Pre-remediation and Post-remediation
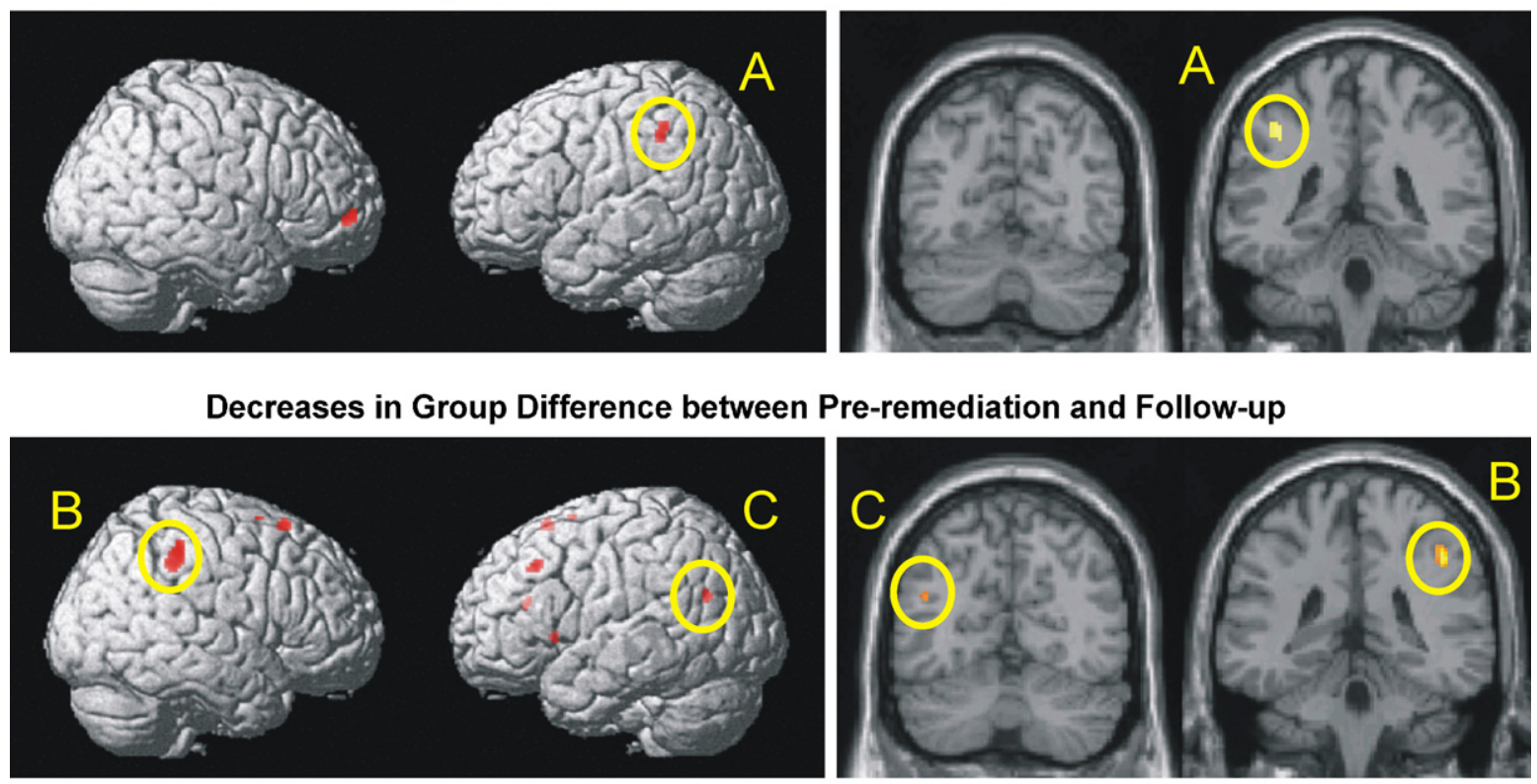

Pre-remediation and Follow-up

$A=$ left inferior parietal, $B=$ right inferior parietal, $C=$ left angular gyrus

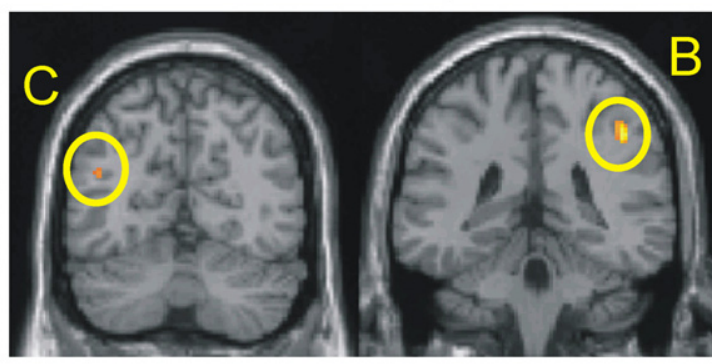

Fig. B.1. Brain areas showing interactions between Group and Phase. Yellow ovals encircle parietal activation. 
groups continued to decrease or increase following the intervention. Clusters showing such an interaction are listed in the lower portion of Table B.1. Probing of the simple main effect of Group at each phase for the peak voxels in the clusters listed in the lower portion of Table B.1 indicated a decrease in the group difference across these two phases in the right supramarginal gyrus (Phase 1 $F(1,26)=13.36, p<.002$; Phase $3 F(1,26)=1.86$, ns), and suggested a similar change in the left angular gyrus (Phase $1 F(1,26)=10.54$, $p=.003$; Phase $3 F(1,26)=0.00, \mathrm{~ns})$. In contrast, the peak voxel in the left putamen showed an increase in the group difference between phases (Phase $1 F(1,26)=2.72$, ns.; Phase $3 F(1,26)=14.09, p<.001$ ). Note that the peak voxel in the left putamen is near the location found in the above analyses involving the contrast between Phases 1 and 2, and the significant group difference in Phase 3 indicates that poor readers maintained higher activation in this area 1 year after the conclusion of the intervention. No other simple main effect of Group within either phase approached significance. Probing of the simple main effect of Phase within each group for the peak voxels listed in Table B.1 revealed that in most regions, poor readers showed a reliable or marginal increase in activation between the pre-remediation and follow-up scans (for the left precuneus $F(1,17)=16.77, p<.001$; for the middle cingulate, $F(1,17)=10.40$, $p<.005$; for the left middle frontal gyrus, $F(1,17)=9.83, p<.006$; for the left angular gyrus, $F(1,17)=10.8, p<.005$; and for the right supramarginal gyrus $F(1,17)=12.72, p<.003)$, whereas good readers showed non-significant trends toward a decrease in activation between these two scans in these same areas (for the left precuneus $F(1,9)=3.35$, ns; for the right middle cingulate, $F(1,9)=4.14$, ns; for the left middle frontal gyrus, $F(1,9)=8.92$, ns; for the left angular gyrus, $F(1,9)=6.04$, ns; and for the right supramarginal gyrus $F(1,9)=8.30, p<.003)$. In contrast, poor readers showed a significant decrease in activation between the two phases in the right precuneus $(F(1,17)=16.14, p<.001)$ and a marginal decrease in the left supramarginal gyrus $(F(1,17)=12.82, p<.003)$, but good readers showed slight increases in these same areas $(F(1,9)=5.08$, ns; and $F(1,9)=7.68$, ns, respectively).

\section{References}

Aylward, E. H., Richards, T. L., Berninger, V. W., Nagy, W. E., Field, K. M., Grimme, A. C., et al. (2003). Instructional treatment associated with changes in brain activation in children with dyslexia. Neurology, 61, 212-219.

Blachman, B. A., Schatschneider, C., Fletcher, J. M., Francis, D. J., Clonan, S. M., Shaywitz, B. A., et al. (2004). Effects of intensive reading remediation for second and third graders and a 1-year follow-up. Journal of Educational Psychology, 96, 444-461.

Booth, J. R., Burman, D. D., Meyer, J. R., Gitelman, D. R., Parrish, T. B., \& Mesulam, M. M. (2004). Development of brain mechanisms for processing orthographic and phonologic representations. Journal of Cognitive Neuroscience, 16, 1234-1249.

Booth, J. R., Burman, D. D., Meyer, J. R., Lei, Z., Choy, J., Gitelman, D. R., et al. (2003). Modality-specific and -independent developmental differences in the neural substrate for lexical processing. Journal of Neurolinguistics, 16, 383-405.

Brunswick, N., McCroy, E., Price, C. J., Frith, C. D., \& Frith, U. (1999). Explicit and implicit processing of words and pseudowords by adult developmental dyslexics: A search for Wernicke's Wortschatz? Brain, 122, 1901-1917.

Chein, J. M., \& Schneider, W. (2005). Neuroimaging studies of practice-related change: fMRI and meta-analytic evidence of a domain-general control network for learning. Brain Research. Cognitive Brain Research, 25, 607-623.

Chen, S. H., \& Desmond, J. E. (2005). Cerebrocerebellar networks during articulatory rehearsal and verbal working memory tasks. NeuroImage, $15,332-338$.

Clark, D., \& Wagner, A. D. (2003). Assembling and encoding word representations: fMRI subsequence memory effects implicate a role for phonological control. Neuropsychologia, 41, 304-317.

Cohen, L., Dehaene, S., Naccache, L., Lehericy, S., Dehaene-Lambertz, G., Henaff, M., et al. (2000). The visual word form area: Spatial and temporal characterization of an initial stage of reading in normal subjects and posterior split-brain patients. Brain, 123, 291-307.

Cohen, L., Lehéricy, S., Chochon, F., Lemer, C., Rivaud, S., \& Dehaene, S. (2002). Language-specific tuning of visual cortex? Functional properties of the Visual Word Form Area. Brain, 125, 1054-1069.

Collette, F., Van der Linden, M., Laureys, S., Delfiore, G., Degueldre, C., Luxen, A., et al. (2005). Exploring the unity and diversity of the neural substrates of executive functioning. Human Brain Mapping, 25, 409-423.
Constable, R. T., Pugh, K. R., Berroya, E., Mencl, E., Westerveld, M., Ni, W., et al. (2004). Sentence complexity and input modality effects in sentence comprehension: An fMRI study. Neurolmage, 22, 11-21.

Corina, D. P., Richards, T. L., Serafini, S., Richards, A. L., Steury, K., Abbott, R. D., et al. (2001). fMRI auditory language differences between dyslexic and able reading children. NeuroReport, 12, 1195-1201.

Cox, R. W., \& Hyde, J. S. (1997). Software tools for analysis and visualization of FMRI Data. NMR in Biomedicine, 10, 171-178.

Cutting, L. E., Clements, A. M., Courtney, S., Rimrodt, S. L., Schafer, J. G. B., Bisesi, J., et al. (2006). Differential component of sentence comprehension: Beyond single word reading and memory. NeuroImage, 29, 429-438.

Davachi, L., Marril, A., \& Wagner, A. D. (2001). When keeping in mind supports later bringing to mind: Neural markers of phonological rehearsal predict subsequent remembering. Journal of Cognitive Neuroscience, 13, 1059-1070.

Dunn, L. M., \& Dunn, L. M. (1997). Peabody picture vocabulary test-revised. Circle Pines, MN: American Guidance Service.

Eden, G. F., Jones, K. M., Cappell, K., Gareau, L., Wood, F. B., Zeffiro, T. A., et al. (2004). Neural changes following remediation in adult developmental dyslexia. Neuron, 44, 411-422.

Friston, K., Ashburner, J., Frith, C., Poline, J. B., Heather, J., \& Frackowiak, R. (1995). Spatial registration and normalization of images. Human Brain Mapping, 2, 165189.

Gayan, J., \& Olson, R. K. (2001). Genetic and environmental influences on orthographic and phonological skills in children with reading disabilities. Developmental Neuropsychology, 20, 483-507.

Georgiewa, P., Rzanny, R., Hopf, J., Knab, R., Glauche, V., Kaiser, W. A., et al. (1999). fMRI during word processing in dyslexic and normal reading children. NeuroReport, 10, 3459-3465.

Hampson, M., Tokoglu, F., Sun, Z., Schafer, R. J., Skudlarski, P., Gore, J. C., et al. (2006). Connectivity-behavior analysis reveals that functional connectivity between left BA39 and Broca'a area varies with reading ability. NeuroImage, 31, 513-519.

Hoeft, F., Hernandez, A., McMillon, G., Taylor-Hill, H., Martindale, J. L., Meyler, A., et al. (2006). Neural basis of dyslexia: A comparison between dyslexic and nondyslexic children equated for reading ability. The Journal of Neuroscience, 26, 10700-10708.

Hoeft, F., Meyler, A., Hernandez, A., Juel, C., Taylor-Hill, H., Martindale, J. L., et al. (2007). Functional and morphometric dissociation between dyslexia and reading ability. Proceedings of the National Academy of Sciences of the United States of America, 104, 4234-4239.

Honey, G. D., Bullmore, E. T., \& Sharma, T. (2000). Prolonged reaction time to a verbal working memory task predicts increased power of posterior parietal cortical activation. NeuroImage, 12, 495-503.

Humphries, C., Binder, J. R., Medler, D. A., \& Liebenthal, E. (2006). Syntactic and semantic modulation of neural activity during auditory sentence comprehension. Journal of Cognitive Neuroscience, 18, 665-679.

Just, M. A., Newman, S. D., Keller, T. A., McEleney, A., \& Carpenter, P. A. (2004). Imagery in sentence comprehension: An fMRI study. Neurolmage, 21, 112-124.

Keller, T. A., Carpenter, P. A., \& Just, M. A. (2001). The neural bases of sentence comprehension: A fMRI examination of syntactic and lexical processing. Cerebral Cortex, 11, 223-237.

Kronbichler, M., Hutzle, F., Staffen, W., Mair, A., Ladurner, G., \& Wimmer, H. (2006). Evidence for a dysfunction of left posterior reading area in German dyslexic readers. Neuropsychologia, 44, 1822-1832.

Lancaster, J. L., Woldorff, M. G., Parsons, L. M., Liotti, M., Freitas, C. S., Rainey, L., et al. (2000). Automated Talairach Atlas labels for functional brain mapping. Human Brain Mapping, 10, 120-131.

Little, D. M., \& Thulborn, K. R. (2006). Prototype-distortion category learning: A twophase learning process across a distributed network. Brain and Cognition, 60, 233-243.

Meyler, A., Keller, T. A., Cherkassky, V. L., Lee, D., Hoeft, F., Whitfield-Gabrieli, S., et al. (2007). Brain activation during sentence comprehension among good and poor readers. Cerebral Cortex, 17, 2780-2787.

Miller, E. K., \& Cohen, J. D. (2001). An integrative theory of prefrontal cortex function. Annual Review of Neuroscience, 24, 167-202.

Nebel, K., Wiese, H., Stude, P., de Greiff, A., Diener, H. C., \& Keidel, M. (2005). On the neural basis of focused and divided attention. Brain Research. Cognitive Brain Research, 25, 760-776.

Noble, K. G., Wolmetz, M. E., Ochs, L. G., Farah, M. J., \& McCandliss, B. D. (2006). Brain-behavior relationships in reading acquisition are modulated by socioeconomic factors. Developmental Science, 9, 642-654

Paulesu, E., Frith, U., Snowling, M., Gallagher, A., Morton, J., Frackowiak, R. S. J., et al. (1996). Is developmental dyslexia a disconnection syndrome? Evidence from PET scanning. Brain, 119, 143-157.

Pugh, K. R., Mencl, W. E., Jenner, A. R., Katz, L., Frost, S. J., Lee, J. R., et al. (2000). Functional neuroimaging studies of reading and reading disability (developmental dyslexia). Mental Retardation and Developmental Disabilities Research Reviews, 6, 207-213.

Pugh, K. R., Mencl, W. E., Shaywitz, B. A., Shaywitz, S. E., Fulbright, R. K., Constable, R. T., et al. (2000). The angular gyrus in developmental dyslexia: Task-specific differences in functional connectivity within posterior cortex. Psychological Science, $11,51-56$.

Rumsey, J. M., Andreason, P., Zametkin, A. J., Aquino, T., King, A. C., Hamburger, S. D., et al. (1992). Failure to activate the left temporoparietal cortex in dyslexia, as measured with oxygen 15 positron emission tomography. Archives of Neurology, $49,527-534$ 
Rumsey, J. M., Nace, K., Donohue, B., Wise, D., Maisog. J. M., \& Andreason, P. (1997). A positron emission tomographic study of impaired word recognition and phonological processing in dyslexic men. Archives of Neurology, 54, 562-573.

Saito, D. N., Yoshimura, K., Kochiyama, T., Okada, T., Honda, M., \& Sadato, N. (2005) Cross-modal binding and activated attentional networks during audio-visual speech integration: A functional MRI study. Cerebral Cortex, 15, 1750-1760.

Samuelsson, S., \& Lundberg, I. (2003). The impact of environmental factors on components of reading and dyslexia. Annals of Dyslexia, 53, 201-217.

Samuelsson, S., Byrne, B., Quain, P., Wadsworth, S., Corley, R., DeFries, J. C., et al. (2006). Environmental and genetic influences on prereading skilles in Austrailia, Scandinavia and the United States. Journal of Education Psychology, 97, 705-722.

Seki, A., Koeda, T., Sugihara, S., Kamba, M., Hirata, Y., Ogawa, T., et al. (2001). A functional magnetic resonance imaging study during sentence reading in Japanese dyslexic children. Brain Development, 23, 312-316.

Shaywitz, B. A., Lyon, G. R., \& Shaywitz, S. E. (2006). The role of functional magnetic resonance imaging in understanding reading and dyslexia. Developmental Neuropsychology, 30, 613-632.

Shaywitz, B. A., Shaywitz, S. E., Blachman, B. A., Pugh, K. R., Fulbright, R. K., Skudlarski, P., et al.(2004). Development of left occipitotemporal systems for skilled reading in children after a phonologically-based intervention. Biological Psychiatry, 55, 926-933.

Shaywitz, B. A., Shaywitz, S. E., Pugh, K. R., Mencl, W. E., Fulbright, R. K., Skudlarski, P., et al. (2002). Disruption of posterior brain systems for reading in children with developmental dyslexia. Biological Psychiatry, 52, 101-110.

Shaywitz, S. E. (2003). Overcoming dyslexia: A new and complete science-based program for reading problems at any level. New York: Alfred A. Knopf.

Shaywitz, S. E., \& Shaywitz, B. A. (2005). Dyslexia (specific reading disability). Biological Psychiatry, 57, 1301-1309.

Shaywitz, S. E., Escobar, M. D., Shaywitz, B. A., Fletcher, J. M., \& Makuch, R. W. (1992) Evidence that dyslexia may represent the lower tail of a normal distribution of reading ability. New England Journal of Medicine, 326, 145-150.

Shaywitz, S. E., Shaywitz, B. A., Fulbright, R. K., Skudlarski, P., Mencl, W. E., Constable, R. T., et al. (2003). Neural systems for compensation and persistence: Young adult outcome of childhood reading disability. Biological Psychiatry, 54, 2533.

Shaywitz, S. E., Shaywitz, B. A., Pugh, K. R., Fulbright, R. K., Constable, R. T., Mencl, W. E., et al. (1998). Functional disruption in the organization of the brain for reading in dyslexia. Proceedings of the National Academy of Sciences of the United States of America, 95, 2636-2641.

Shomstein, S., \& Yantis, S. (2004). Control of attention shifts between vision and audition in human cortex. The Journal of Neuroscience, 24, 10702-10706.
Shomstein, S., \& Yantis, S. (2006). Parietal cortex mediates voluntary control of spatial and nonspatial auditory attention. The Journal of Neuroscience, 26, 435-439.

Simos, P. G., Breier, J. I., Fletcher, J. M., Bergman, E., \& Papanicolaou, A. C. (2000). Cerebral mechanisms involved in word reading in dyslexic children: A magnetic source imaging approach. Cerebral Cortex, 10, 809-816.

Simos, P. G., Fletcher, J. M., Bergman, E., Berier, J. I., Foorman, B. R., Castillo, E. M., et al. (2002). Dyslexia-specific brain activation profile becomes normal following successful remedial training. Neurology, 58, 1203-1213.

Stanovich, K. E., \& Siegal, L. S. (1994). Phenotypic performance profile of children with reading disabilities: A regression-based test of the phonological-core variabledifference model. Journal of Educational Psychology, 86, 24-53.

Temple, E., Deutsch, G. K., Poldrack, R. A., Miller, S. L., Tallal, P., Merzenich, M. M., et al. (2003). Neural deficits in children with dyslexia ameliorated by behavioral remediation: Evidence from functional MRI. Proceedings of the National Academy of Sciences of the United States of America, 100, 2860-2865.

Torgesen, J. K., Myers, D., Schirm, A., Stuart, E., Vartivarian, S., \& Mansfield, W., et al. (2006). Closing the Reading Gap: First year findings from a randomized trial of four reading interventions for striving readers. Vol. II: National Assessment of Title I: Interim Report to Congress, Institute of Education Sciences. Available at: http://www.ed.gov/rschstat/eval/disadv/title1interimreport/index.html.

Torgesen, J. K., Wagner, R. K., \& Rashotte, C. A. (1999). Test of Word Reading Efficiency (TOWRE). Austin, TX: Pro-ed.

Tzourio-Mazoyer, N., Landeau, B., Papathanassiou, D., Crivello, F., Etard, O., Delcroix, N., et al. (2002). Automated anatomical labeling of activations in SPM using a macroscopic anatomical parcellation of the MNI MRI single-subject brain. Neurolmage, 15, 273-289.

Vellutino, F. R., Scanlon, D. M., \& Lyon, G. R. (2000). Differentiating between difficultto-remediate and readily remediated poor readers: More evidence against the IQ-achievement discrepancy definition of reading disability. Journal of Learning Disabilities, 33, 223-238.

Vellutino, F. R., Fletcher, J. M., Snowling, M. J., \& Scanlon, D. M.(2004). Specific reading disability (dyslexia): What have we learned in the past four decades? Journal of Child Psychology and Psychiatry, 45, 2-40.

Wagner, R., \& Torgesen, J. (1987). The nature of phonological processes and its causal role in the acquisition of reading skills. Psychological Bulletin, 101, 192-212.

Woodcock, R. W., McGrew, K. S., \& Mather, N. (2001). Woodcock-Johnson III Tests of Achievement. Itasca, IL: Riverside Publishing.

Woodward, T. S., Cairo, T. A., Ruff, C. C., Takane, Y., Hunter, M. A., \& Ngan, E. T. (2006). Functional connectivity reveals load dependent neural systems underlying encoding and maintenance in verbal working memory. Neuroscience, 28 317-325. 